\title{
The Impact of Different Modes on Building learming objects when Designing E-lessons on Achievement, Attitude, and Time
}

\section{Samy Abdelwahab Safaan}

head of Department of Natural and Applied Sciences, Consultant Deanship of e-learning Qassim University, Assistant Professor Computer Sciences, Nile Higher Institute for Business Technology in Computer Sciences

\section{Abstract:}

7 he purpose of this paper is to examine and present in an orderly fashion the implications of various approaches to the development of learning objects (e.g., instruction, collaboration, practice with hints, and assessment). To promote the learning of variables, types of data, control statements and loops, learning objects were developed in Learning Management System (LMS) E-lessons by college students who are enrolled in a visual programming course. The process of development involved one of the following four approaches: an approach based on instruction, practice with hints, collaboration and evaluation; an approach based on collaboration and practice with hints; an approach based on instruction, collaboration, and evaluation; and an approach based exclusively on instruction. In contrast to learning modules without e-learning practice on posttests, according to the sample findings, the learning modules with e-learning practice performed better. The attitudes of the group with practice were also more positive. Further, unlike the samples that use instruction only, the samples with complete learning approaches took longer to finish the E-lessons.

Keywords:Learning management system, E-lessons, learning objects, e-learning

\section{Introduction}

The current era is characterized by rapid and innovative change that has developed with the progress of science and its applications. Education systems are trying to cope with the challenges that students face by using innovative teaching methods to prepare them to use the modern technology that is required to gain access to large amounts of information through five daily lectures (Aitchanov, Nussipbekov, \& Zhaparov, 2012). 
It may be difficult for some students to study a lesson or unit that takes 1-2 hours to learn. Most universities and colleges worldwide, including those in Saudi Arabia, offer courses for 1018 teaching weeks per semester. Learning in such short periods with multiple courses places an additional burden on students.

\section{Research problem}

Programming courses are required to provide the knowledge and skills that are required to produce complete projects in the process of learning and teaching during this period. Some people think that programming is a barrier that stops them from continuing to study. Learning and teaching can be challenging without such skills, and the majority of students withdraw from their studies due to a lack of programming knowledge (Esteves, Fonseca, Morgado, \& Martins, 2011; Gomes, Areias, Henriques, \& Mendes, 2008; Malik, 2008).

Programming languages like $\mathrm{C}++$, Pascal and visual basic.net have wide and complex Instructions and learn programming depends on the understanding of concepts, coding and implementation of this knowledge to build program instructions easily as emphasized by both Gomes and Mendes (2007) who confirmed that novices are having difficulty in the use of basic concepts such as pseudo code and algorithms to solve programming problems. Understanding the basic programming concepts, like differences between constants and variables, Data Types, Control Statements and Loops, is essential for novice students order to write a complete program.

Most of the previous scientific literature has found that there are many reasons for the unwillingness of students in programming courses; they find that the content is incomprehensible and that traditional teaching methods rely heavily on theoretical lectures and focus on imparting declarative knowledge. At the same time, the large quantity of information, the lack of appropriate support (Elgamal, Abas, \& Baladoh, 2013; Esteves et al., 2011; Gomes et al., 2008; Malik, 2008; Radoševic, Orehovacki, \& Lovrencic, 2009), and the growing awareness of the causes of these challenges are the most 
important trends in ongoing and future research (Henderson, 2007; Jeffrey \& Tricia, 2011; Matthews, 2014; Siti, 2012).

Žufic \& Jurcan (2015) found many tools that can be very useful, especially for students who need support, to help them to learn programming, but such tools and methods are not effective with most learners because they depend on the willingness and ability of the learner to conduct appropriate research on proposed solutions to problems. Hence, many students have difficulties using such tools.

The tools that are used in learning management systems (LMS) connect with students continuously. One of the most recent trends in this field is micro-learning, which has been established as an innovative process of educating. Micro learning involves the division of content into small chunks to minimize cognitive overload (Epignosis, 2014).

\section{Research questions}

The basic research questions for this study are as follows:

1. How are attitudes, achievement and time affected by practice with hints among students learning via E-lessons on LMS?

2. What are the effects of the collaboration and assessment on time, attitude and achievement when students learn by E-lessons on LMS?

3. Do practice with hints and collaboration and/or assessment have any degree of effect on attitude, achievement and time?

\section{Aims of the current study}

Several studies have focused on the survey of the effect of a single learning object. The results of these studies demonstrate that the presence of the object under study contributed to improved student learning. However, other results have indicated that the effects of these objects decrease significantly when they are combined with other objects in a lesson. Additionally, few studies have focused on the examination of the 
effect of learning objects in teaching and learning programming languages.

The purpose of this study is to establish the effect and/or impact of different modes on the building of learning objects in E-lessons on LMS. In this study, the instruction mode remains uniform across all four types of learning modes that are used in the construction of E-lessons because instruction mode is a basic mode in learning that cannot be avoided. The other learning modes that are used in the study include collaboration, practice using hints and assessments, which have been combined in different learning modes in the design of E-lessons on LMS in a manner that allowed the impact of the design of E-lessons on LMS to be investigated in several scenarios, i.e., when a practice mode with hints was removed and present only in instruction mode and when all of the learning modes were present.

\section{Review of literature}

\section{Micro-learning}

The main goal of the micro-learning process is to fragment complex information into smaller pieces that support learning to accomplish a single learning outcome. Students can grasp smaller pieces of information in 10 to 20 minutes and can practice these units. When they know enough about an information or skill, students will be able to understand more complex information that is related to a given subject (Aitchanov et al., 2012).

There are many books that explain programming courses, but most of them are complex and comprehensive. The use of technological tools such as forums, blogs, wiki, video and reading tutorials can be beneficial for students in the process of the micro learning (Saparkhojayev, 2013).

Micro-learning contains lessons or short units in the form of textual, audio or film materials. Learning can be administered through question-and-answer quizzes, problem solving or the preparation of small projects. These short units of content can be presented by text or audio and are designed to be as efficient as 
possible (Fernandez, 2014; Vodeclic, 2015). Žufic \& Jurcan (2015) described micro-learning as an online learning and training methodology that employs short videos ( 5 to 10 minutes at the most) that are rich in images, text and audio that have been designed using the principle of performance-based learning.

\section{Micro-learning versus classic E-teaching}

Micro-learning is an easy method of e-learning and, by extension, even mobile learning (m-learning) compared to classic E-teaching. An extensive literature review shows that there are differences between micro learning and classic E-teaching, as shown in the following Table 1.

Table 1. Micro-Learning Versus Classic E-teaching

\begin{tabular}{|l|l|l|}
\hline Item & Micro-learning & Classic E-teaching \\
\hline Lessons & $\begin{array}{l}\text { Short time (10-20 } \\
\text { minute) }\end{array}$ & $\begin{array}{l}\text { Long time (50 minute } \\
\text { or longer) }\end{array}$ \\
\hline Content & Easily changed & $\begin{array}{l}\text { Constant rarely } \\
\text { changing }\end{array}$ \\
\hline Material development & Rapidly progressing & $\begin{array}{l}\text { Slowly or qualitative } \\
\text { up-gradation cannot be } \\
\text { done }\end{array}$ \\
\hline $\begin{array}{l}\text { Value enhancement } \\
\text { and redesign }\end{array}$ & Cheap & Considerably costly \\
\hline Aggregation & $\begin{array}{l}\text { Consists of teaching } \\
\text { materials, units and } \\
\text { themes }\end{array}$ & $\begin{array}{l}\text { Split into additional } \\
\text { micro } \\
\text { units }\end{array}$ \\
\hline participants learn & $\begin{array}{l}\text { Short teaching } \\
\text { materials }\end{array}$ & $\begin{array}{l}\text { Long teaching } \\
\text { materials }\end{array}$ \\
\hline
\end{tabular}

\section{The benefit of micro-learning}

Many studies have indicated that micro-learning has various benefits when it is used in educational settings (Fernandez, 2014; Job \& Ogalo, 2012; Saparkhojayev, 2013; Žufic \& Jurcan, 2015). The benefits are listed as follows:

It provides information or skills to students in the form of small pieces, reduces the cognitive load and simplifies the material. It provides an opportunity for learners to obtain the courses information anywhere and at any time, and they can easily interact with the other parties in the educational process. 
It helps students focus on specific information or skills, which are beneficial for remembering and recalling abilities, and it can be easily used in any other scenario.

It promotes active and quick learning by using various mobile devices such as smart phones, tablets, laptops, and notebook computers.

It makes learning interesting and attractive through the presentation of information and skills in different forms such as videos, images and audio.

The design and construction of micro-learning is less expensive and can be upgraded easily.

It helps lecturer's courses identify students' trends and tendencies by providing feedback.

\section{Methods and technicalities Integrate Micro-learning into learning and teaching}

E-learning is well-suited to deliver Micro-learning , because it is easily joined with Web 2.0 Technologies that can be used in LMS to manage learning and communication with student on multiple devices. Here's a partial list of "Methods and technicalities" that are well-suited in Micro-learning for the advancement of teaching:

video-clips and podcasts: There are many benefits to using videos in education. Videos have given a new dimension in teaching and learning, especially with the increase in internet speed it can be considerably effortless to tape and upload videos using YouTube or LMS, and students can get these any moment, anywhere where ever they want. Podcast is a form of digital media containing educational content in the form of audio or audio-video recordings (Fernandez, 2014; Pappas, 2014).

Games and micro-games: Learning masqueraded as games is fun. Most of the scientific literature suggests that children can learn better and most effectively through playing. It allow students the chance to interact with the subject matter of the lesson through a different interface (Chattopadhyay, 2015). 
Assessments and quizzes: Tests can provide an assessment of the student's knowledge as well as set a bar for increasing the degree of knowledge and skill against a standard. To divide students into subgroups and challenge them to create collaborative social quizzes to test each other, allows improvement in the understanding of academic materials and the students' skills (Epignosis, 2014).

Educational blogs and articles: Encourage students to create articles that teach how to do something. Students can access blogs and acquire information whenever and on whatever topic they require it (Žufic \& Janko, 2105).

Multimedia presentations: Induce students to create and share visual slides, presenting micro-lessons in a short time span of several minutes and multimedia presentations effective in education is quite substantial, which help students to understand terms or concepts.

Educational simulations and case studies: Simulations are imitations that put one in the mind of real environments and have proven highly effective as a method of education. Allowing perception of information in a certain manner, it enables students to build and enhance their skills with a more creative understanding of data. This creates real-life stories related to education problems (Pappas, 2014).

\section{Micro-Learning Object Structure (video)}

Video is one of the most commonly used micro-learning objects in E-learning. It is facilitated by high-speed internet connections and the use of mobile phones and other smart devices. Video has the capacity to deliver a range of information and skills (Hansch et al., 2015). Video is the most effective medium for communicating information in a short period of time. It is immensely effective for performance-based training (Huo \& Shen, 2015).

\section{The elements of micro-learning objects (video)}

A micro-learning object expresses the instructional content objectives, and an educational object consists of three 
interconnected parts that are designed to achieve a particular instructional objective, as identified by Matthews (2014). These interconnected parts are as follows:

- Learn: The display information to be learned.

- Practice: The direct application of the learned information.

- Assess: The testing and the scope of the objective to be learned and the student's understanding of it.

Abdel Basset (2011) believes that all instructional objects contain the following elements:

- Objective: Describes the desired result that is accessible from the learning activity.

- Learning Activity: The method or mental or physical effort by which the objective is achieved.

- Assessment: Determines whether the objective has been achieved.

From the above, it can be concluded that the instructional object is an independent object that has a specific objective and instructional activity that works to achieve that objective and it includes assessment to examine and ensure that the objective has been attained.

In the present research, the researcher used the division (Learning Circuits, 2005) of learning devices including instruction, practice, collaboration and assessment to form separate types of learning modules. The researcher used the video object in E-lessons design, where the researcher select articulate storyline 2 program. It captures and saves a full video recording which in the form of one or more of the four learning modules, can be made part of the E-lessons this is illustrated in the following:

- Instruction mode: It is a video contained lessons; objective and basic information on a single slide.

- Collaboration mode: it's contained course communication between course members. The messages 
between course members are private and secure so the users must be logged onto the course on blackboard LMS. The system is somewhat similar to email.

- Practice with hints mode: It is video contained practice with providing hints, through viewing each action step by step and every action is translated into its separate slide.

- Assessment mode: It is a video contained results can be tracked (Once a student executes steps properly or advances beyond a set mark, the slide advances) with feedback or not.

\section{Method}

This research employed a post-test experimental design underpinned by a $2 \times 2$ bacterial model. Collaboration and/or assessment learning and practice represent the independent variables, which are classified according to their presence or absence. The dependent variables included post-test performance, student attitude and duration of learning (Mathews, 2014; Abdel Basset, 2011). Four categories of learning approaches were employed in the creation of E-lessons on LMS: a learning approach based on practice with hints, collaboration, instruction and assessment; a learning approach based on collaboration and practice with hints; a learning approach based on instruction, collaboration and assessment; and a learning approach based exclusively on instruction (Mathews, 2014; Abdel Basset, 2011). Each of these was allocated at random to the research samples.

\section{Sample Size}

A total of 96 students who were enrolled in the level II computer science program at Buraydah Community College at Qassim University were included in the research sample. Although they were divided into four groups, the teaching based on the course curriculum was collective. The college laboratory was booked for the duration of the research. 


\section{Procedures}

Both verbal announcements and notifications on Blackboard LMS, a form of online messaging, were given at the start of the first semester $(2015 / 2016)$ week to students of the level III computer science degree who were registered in the visual programming Cos 211 course. In agreement with the faculty computer department and the deanship of student affairs at Qassim University, 10 grades were added to the quarterly grades for students who took part in the present study. During the second week of the semester, two E-lessons (variables, data types, control statements and loops) commenced, and in the fourth week of the semester the participants were informed of how they had performed in the two E-lessons on blackboard LMS. For these E-lessons, each of the four learning approaches (i.e., instruction, collaboration, practice with hints, and assessment) was allocated 60 minutes. The E-lessons structure for the full learning approach is illustrated in Figure 1. The same procedures were used for each of the four experimental groups regarding the post-test and attitude survey that was announced on the Blackboard LMS. Ten participants were chosen to undertake a formative assessment of the learning approaches. The slight errors that were uncovered in this evaluation were addressed before the study was initiated. The evaluation also showed that the ten participants had an average post-test score of 17.5 out of the maximum 24 (72.9\%).

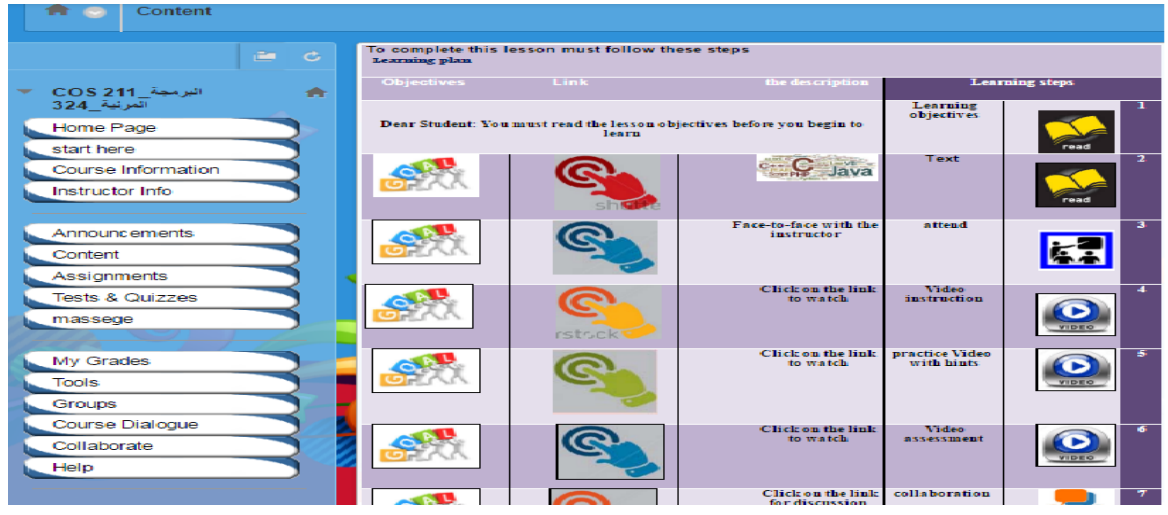

Figure 1 the plan for learning the E- lessons 


\section{Criterion and Enroute Arrangement}

The study sample of the four experimental groups were divided randomly, and post-test study tools and an attitude survey were applied. A pre-was also used test to determine prior knowledge.

\section{Pre-test}

The tool used to assess the participants' subject knowledge was a set of pre- and post-tests before any instructions were given to the participants to whom the tests were assigned randomly within ability blocks. The pre-test comprised 24 MCQs (multiple choice questions) that covered the relevant course contents. The pre-test displayed a total mean score of 9.88 or $41 \%$, which showed the inability of the participants regarding content before they received any directions. A one-way analysis of variance (ANOVA) revealed that there was not much difference among the four treatment groups in the pre-test.

\section{Post-test}

The 24 MCQs from the pre-test were the same as those on the post-test. Because the latter was undertaken following a three-week intermission and in the absence of pre-test feedback, the post-test results were presumed to be influenced by the pretest. A reliability score of 0.80 was established for the post-test.

\section{Attitude Survey}

To determine how the use/non-use of a learning object element affected attitudes towards visual programming, an attitude survey was conducted among the research groups. The E-lessons full learning approach comprised three videos, each of which constituted one element of the learning object. The survey included 12 questions that were presented on the basis of a 5point Likert scale and were intended to determine participants' perceptions of the learning approaches that underpinned the object that was employed to develop the E-lessons on LMS. Six elements of these approaches were compared. A reliability score of 86 was established for this survey. 
The amount of time that was spent watching the videos for all four learning approaches and completing the full learning approach was calculated for every participant.

\section{Data analysis}

The data were analysed with one-way ANOVA. A distinct dependent measurement was employed in the form of the amount of time that was attributed to the learning approaches and the analysed data from the 12 survey questions based on the Likert scale. To determine the participants' views about whether the learning objects helped their learning process, Chi-square tests (items 13-18) were conducted. An analysis of the openended questions 19-20 regarding learning approaches was also carried out.

\section{Results}

\section{Achievement}

The post-test had a standard deviation of 3.29 and a mean score of 18.96 out of 24 items, as shown in Table 2 . The highest mean score (20.14) and standard deviation (2.08) were associated with the research groups that undertook every one of the four learning approaches. By contrast, the lowest mean score (18.36) and standard deviation (3.01) were associated with the groups that undertook all of the learning approaches apart from practice with hints. The analysis of the post-test performance with one-way ANOVA revealed that practice with hints, which displayed a considerable main effect with a $\mathrm{F}$ of 9.54, a degree of freedom of 1.92, an effect size of $\eta 2$ equivalent to 0.095 and a 10.32 mean square error. Neither the correlation of collaboration and/or assessment and practice with hints nor simple collaboration and/or assessment exhibited a substantial effect.

Table 2. Statistical Measures of Post-test Scores by Treatment

\begin{tabular}{|c|c|c|c|}
\hline \multicolumn{4}{|c|}{ Practice with hints } \\
\hline Yes & No & Total \\
\hline Collaboration/assessment & 20.14 & 18.36 & 19.25 \\
Yes & $(2.08)$ & $(3.01)$ & $(2.86)$ \\
\hline No & 19.03 & 18.31 & 18.67 \\
\hline Total & $(2.96)$ & $(3.76)$ & $(3.62)$ \\
\hline & 19.59 & 18.34 & 18.96 \\
\hline
\end{tabular}

Note: Maximum possible post-test score was 24 . 


\section{Time in learning modes}

The amount of time allocated to the learning approaches is detailed in Table 3. The average duration that the groups assigned to different learning approaches spent on learning lessons was 42:24 minutes. The least amount of time (31:32) spent on learning was associated with the group that only received instruction. Furthermore, the group that was assigned collaboration and assessment alongside additional methods spent 35:48 minutes on learning. The group without practice with hints but with a range of other learning approaches spent 33:44 minutes on learning.

To determine whether the discrepancy between groups with and without practice with hints was significant, a 2X2 ANOVA test was applied. The values obtained were $6.68 \mathrm{~F}$, a 92 degree of freedom, an effect size of $\eta 2$ equivalent to 0.068 , and a mean square error of 57.72. The discrepancy between the groups with and without collaboration and/or assessment was also analysed, with values of $3.79 \mathrm{~F}, 92$ degrees of freedom, an effect size of $\eta 2$ equivalent to 0.039 and a mean square error of 57.72 .

Table 3. The Time Spent in Learning Modes

\begin{tabular}{|c|c|c|c|}
\hline \multicolumn{3}{|c|}{ practice with hints } \\
\hline & Yes & No & Total \\
\hline Collaboration /assessment & & & \\
Yes & $42: 24$ & $33: 44$ & $37: 34$ \\
\hline No & $35: 48$ & $31: 32$ & $33: 40$ \\
\hline Total & $38: 36$ & $32: 38$ & $35: 37$ \\
\hline
\end{tabular}

Note: The table values have been calculated by minutes and seconds.

\section{Student Attitudes}

As shown in Table 4, the highest (4.1) and lowest (3.99) means derived from the attitudes survey were associated with the group that received collaboration and/or assessment and the group that did not, respectively. The overall mean of 4.03 suggested that the E-lessons and related learning approach were perceived favourably by the participants. The items 'the video in the E-lessons helped my learning' and 'I would enjoy using other E-lessons such as this in future courses' were rated highest 
(4.25) and lowest (3.80), respectively. To determine the impact of practice on them, the survey items were analysed and revealed that practice was useful because it consolidated learning.

According to the univariate assessment of every object of the attitude survey, the item 'the E-lessons provided enough opportunity to practice the topic with tips' was significantly influenced by practice with hints, as revealed by the values of 4.18 for $F(3,92)$, an 0.05 significance level, a 0.04 impact coefficient, and a 0.721 mean square error. Meanwhile, the item 'I knew that I should ask for the guidance of my colleagues and a professor who was scheduled in any section of the E-lessons ' was considerably influenced by collaboration and/or assessment, with values of 4.89 for $F(3,92)$, a significance level below .05 , a 4.04 impact coefficient, and a 2.58 mean square error. The remaining ten Likert-type items in the attitude survey did not produce notable results.

To determine the perceived efficacy of the different learning approaches on the acquisition of learning objects, items 13-18 in the mindset survey were paired for comparison, and the implications of such pairings were assessed through chi-square tests. The findings are presented in Table 5, with three results being particularly notable. The participants believed that the approaches of practice with hints, assessment, and instruction were all more useful than collaboration.

The open-ended questions 19 and 20 in the attitude survey were intended to measure what participants thought to be the strengths and weaknesses of the E-lessons. The results showed that 30 participants had a clear preference for videos, whereas 9 and 10 participants preferred practice and ease of use and accessibility, respectively. The E-lessons duration and repetitive content were criticised by 11 and 10 of the participants, respectively.

\section{Discussion}

The impact of learning object modes (such as assessment collaboration, practice with hints, and instruction) on attitudes, 
time in program and achievements is evaluated in this study. This study was conducted with a sample of students of computer programming at Buraydah Community College at Qassim University. Lessons in visual programming (COS 211) on the LMS were used. The 2 lessons were different based on the absence or presence of practice with hints and collaboration and/or assessment.

Table 4. Attitude Scores by Treatment

\begin{tabular}{|c|c|c|c|c|c|}
\hline Survey Items & 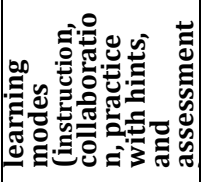 & 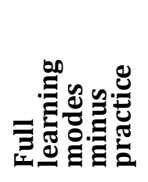 & 象 & ס̊ & Total \\
\hline $\begin{array}{l}\text { The use of collaboration in } E- \\
\text { lessons was clear to me }\end{array}$ & 4.12 & 4.16 & 4.07 & 4.09 & 4.11 \\
\hline $\begin{array}{l}\text { The E-lessons gave me } \\
\text { sufficient time to practice } \\
\text { the material * }\end{array}$ & 4.11 & 3.91 & 4.03 & 3.72 & 3.94 \\
\hline $\begin{array}{l}\text { Assessment enabled } \\
\text { understanding of the content } \\
\text { in } e \text { - lessons }\end{array}$ & 4.08 & 4.11 & 4.06 & 4.13 & 4.09 \\
\hline $\begin{array}{l}\text { I knew he could ask for the } \\
\text { support of my colleagues } \\
\text { and a professor scheduled in } \\
\text { any section of the E- lessons } \\
*\end{array}$ & 4.12 & 4.18 & 3.98 & 4.01 & 4.07 \\
\hline $\begin{array}{l}\text { The practice in the E-lessons } \\
\text { helped me learn the content }\end{array}$ & 4.01 & 4.05 & 4.19 & 3.87 & 4.03 \\
\hline $\begin{array}{l}\text { The assessment at the end of } \\
\text { each section helped my } \\
\text { learning }\end{array}$ & 4.07 & 4.13 & 4.09 & 3.89 & 4.04 \\
\hline $\begin{array}{l}\text { The instruction in the E- } \\
\text { lessons helped my learning }\end{array}$ & 4.01 & 4.16 & 4.13 & 4.11 & 4.10 \\
\hline $\begin{array}{l}\text { The video in the E-lessons } \\
\text { helped my learning }\end{array}$ & 4.21 & 4.3 & 4.28 & 4.24 & 4.25 \\
\hline $\begin{array}{l}\text { I learned a lot from these E- } \\
\text { lessons }\end{array}$ & 3.71 & 4.16 & 3.98 & 3.76 & 3.90 \\
\hline $\begin{array}{l}\text { Quality of the E-lessons was } \\
\text { generally satisfactory }\end{array}$ & 4.13 & 4.11 & 4.03 & 4.1 & 4.09 \\
\hline $\begin{array}{l}\text { These E-lessons } \\
\text { recommended to } \\
\text { students }\end{array}$ & 4.01 & 4.02 & 3.89 & 4.12 & 4.01 \\
\hline $\begin{array}{l}\text { I would like to use similar E- } \\
\text { lessons in future courses }\end{array}$ & 3.62 & 3.91 & 3.81 & 3.88 & 3.80 \\
\hline Total & 4.016 & 4.1 & 4.04 & 3.99 & 4.03 \\
\hline
\end{tabular}

Note: One equals strongly disagree, two equals disagree, three equals neither agree nor disagree, four equals agree and five equals strongly agree

* Significance level less than 0.05 . 
We can conclude from the results that performance was significantly affected only by practice with hints, and not by collaboration and assessment. Indeed, compared with the research group that did not apply practice with hints, the one that did displayed higher learning performance. Learners who used practice not only were capable of undertaking tasks comparable to those who were evaluated post-test, but they also attained good results. .Previous studies reported similar results (e.g. Gagné, Wager, Golas, and Keller, 2005), confirming that learners are more likely to accomplish the learning goals if they engage in practice (Martin, Klein and Sullivan, 2007). Furthermore, it has been argued that practice enables learners to consolidate newly acquired knowledge (Foshay, Silber and Stelnicki, 2003) as well as to better understand and retain new information (Klein, Spector, Grabowski and de la Teja, 2004). On the other hand, Merrill (2002) contended that it is only when knowledge and attitudes are embodied in objectives that practice has efficiency.

Table 5. A Comparison between the Attitude Data for Learning Mode

\begin{tabular}{|c|c|c|c|c|c|}
\hline $\begin{array}{l}\text { Which of these two things helped you to learn from } \\
\text { the E-lessons? }\end{array}$ & 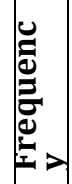 & $z$ & & 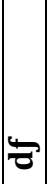 & 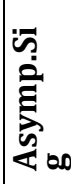 \\
\hline Collaboration or practice with hints & $\begin{array}{l}2 \\
8\end{array}$ & $\begin{array}{l}6 \\
8\end{array}$ & 16.6 & 1 & O \\
\hline Collaboration or assessment & $\begin{array}{l}2 \\
\mathbf{0}\end{array}$ & $\begin{array}{l}7 \\
6\end{array}$ & $\begin{array}{l}32.6 \\
7\end{array}$ & 1 & $\mathbf{0}$ \\
\hline Collaboration or instruction & $\mathbf{2}$ & $\begin{array}{l}7 \\
3\end{array}$ & $\begin{array}{l}26.0 \\
1\end{array}$ & 1 & O \\
\hline practice with hints or assessment & $\begin{array}{l}4 \\
5\end{array}$ & $\begin{array}{l}5 \\
1\end{array}$ & $\begin{array}{l}0.37 \\
5\end{array}$ & 1 & $\begin{array}{l}0.5 \\
4\end{array}$ \\
\hline Instruction or practice with hints & $\begin{array}{l}4 \\
3\end{array}$ & \begin{tabular}{|l|l}
5 \\
3
\end{tabular} & $\begin{array}{ll}1.04 \\
2\end{array}$ & 1 & $\begin{array}{l}0.3 \\
0\end{array}$ \\
\hline Instruction or assessment & $\begin{array}{l}4 \\
4\end{array}$ & $\begin{array}{l}5 \\
2\end{array}$ & $\begin{array}{l}0.66 \\
7\end{array}$ & 1 & $\begin{array}{l}0.4 \\
1\end{array}$ \\
\hline
\end{tabular}


Once they responded to every practice item, the participants were provided with hints for validations. Positive comments were made when the answers were right, and encouragement was offered when the answers were wrong. Many authors support the efficiency of this type of tactics enhance the (Mathews, 2014; Abdel Basset2011).

In the present study, practice with hints had a much stronger influence on performance than did collaboration and assessment. This is congruous with what Martin, Klein and Sullivan (2007) observed, namely, that the use of a more effective learning object in E-lessons on LMS diminishes the advantages of less effective learning objects. Although theoretical models have extended standards for the circumstances of collaborative skill development by learners, empirical support is insufficient. Indeed, such anticipations could damage the learning process in a collaborative context. Collaboration among learners is shaped by several aspects, including personality differences and individual traits, group organisation and the type of task that needs to be undertaken. Some learners prefer to avoid collaboration and work independently, harbouring distrust for other group members (Huertas Barros, 2011; Klimkowski, 2006).

The present study employed an e-lesson assessment procedure that involved determining the capability of learners to remember steps on their own to apply the same skills and writing code that was acquired during instruction. The successful completion of a step or exceeding a number of possible attempts leds to screen advance. The ranking of steps was comparable to that of questions. The significance of assessment derives from the fact that it facilitates skill development through trial and error and the accumulation of knowledge. However, knowledge and skill acquisition through instruction without practice is not sufficient, and does it not promote high learning performance (Henderson, 2007). E-lessons were favourably received by the majority of the participants, as suggested by the endorsement of statements such as 'e-lesson helped my learning'. 
Several observations can be made regarding the participants answers in the attitude survey. The absence and/or presence of the examined learning objects were acknowledged by the participants. Minimum and maximum approval was cited by the groups that received the instruction-only learning approach and the groups that received practice with hints, respectively. The latter expressed strong agreement with the statement 'The E-lessons gave me sufficient time to practice the material.' Similarly, the group that was given the collaboration learning approach agreed widely with the statement 'I knew he could ask for the support of my colleagues and a professor scheduled in any section of the E- lessons.' Based on these results, it can be deduced that learners are aware of the absence of practice and collaboration from E-lessons and that their performance may consequently suffer.

The efficiency of practice with hints, instruction and assessment was found to be higher than that of collaboration, based on the outcome of the paired comparison question. Whereas for the learning approaches of instruction, practice with hints and assessment the E-lessons included videos, collaboration relied only on messages among the learners. Moreover, although only statistically significant $(p=0.054)$, the efficiency of practice with hints was considered to be higher than instruction and assessment.

The answers from the open-ended questions that were included in the attitude survey revealed that learners were both interested in and attentive to hints. Furthermore, the content was found to be appealing and the progress was uncomplicated.

By contrast to the instruction-only approach, the full learning approach was considered to be the most timeconsuming, involving a lengthy process of completing the Elessons. The former consisted of just one video screen with 40 displays, whereas the latter comprised three video screens with 70 displays. 
Groups that did not receive practice with hints spent less time working on E-lessons than the groups which did receive it. Likewise, groups that did not receive collaboration and assessment finished the E-lessons faster than the groups which did receive those learning methods. In other words, the duration of the learning process is increased by collaboration/assessment and practice with hints. Be that as it may, practice with hints is the only learning approach that stimulates performance, as confirmed by this study and many others.

The present study makes a valuable contribution to the structuring of E-lessons on LMS. In keeping with Martin et al. (2007), this study has revealed that the formation of student attitudes and the accomplishment of learning goals depend to an overwhelming extent on practice with hints. Therefore, E-lessons should incorporate this approach. The learning approaches of collaboration and assessment need additional systematic investigation in a controlled environment of instruction because this study did not find them to contribute significantly to learning performance. Furthermore, different variables, including subject difficulty, student age, and learning motivation, should be considered in relation to the impact of these approaches.

\section{Applicability in other Fields}

Scholars suggest that micro-learning as exhibited in the current study has its applications in many academic fields $(\mathrm{Vu}$, Fredrickson, \& Moore, 2017). Micro-learning and its various modes - as discussed and demonstrated in this study - are simply a medium of delivering pedagogical content to students, similar to a blackboard and a teacher giving a lecture. Teachers of any subject, teaching on any level can develop videos and presentations, upload them on a micro-learning application like Blackboard LMS, and students can access and use the content to aid their learning. The only restriction to the effectiveness of this setup is the teacher's ability to develop videos and presentations, and the students' ability to use the requisite micro-learning software 


\section{Conclusion}

The current study analyses the impact of the difference in the learning object modes using video and other multimedia elements and their impact on the educational process. These studies should be implemented in courses other than computer science. Finally, research on learning object modes should be conducted amongst diverse age-groups. It should be kept in mind that because this study features college students as subjects, young learners may show different results for the effects and assessment in a collaboration practice with hints. To further explore the use of well-designed E-lessons, research should continue beyond this the area.

\section{Acknowledgements}

The authors wish to thank the computer department faculty and the deanship of student affairs at Qassim University for their assistance in mounting this study

\section{Access to Data}

The relevant data sets that were collected during this research will be made openly available through the University of Qassim 's online repository.

\section{Ethics}

This research project was approved by the University of Qassim ethics committee, prior to the commencement of the collection of data. In addition, the project was approved and supported by the buraydah community college.

\section{References}

Aitchanov, B., Nussipbekov, A., \& Zhaparov, M. (2012). Microlearning of web fundamentals based on mobilelearning. International Journal of Computer Science Issues (IJCSI), 9, 6, 148.

Abdel Basset, H. M. (2011). (2011). Digital learning modules: A new technology for education. the world of books, Cairo. Retrieved 
February 11, 2015, from http://hussainbaset. blogspot.com/ 2011/11/blog-post_20.html

Chattopadhyay, Sahana (2015). Micro-Learning as a Workplace Learning Strategy, Blog, Retrieved February April 1, 2015, from http://idreflections.blogspot.ca/2015/04/micro-learningas-workplace-learning.html

Elgamal, A. F., Abas, H. A., \& Baladoh, E. -M. (2013). An interactive e-learning system for improving web programming skills. Education and Information Technologies, 18, 1, 29-46 doi:10.1007/s10639-011-9175-7.

Epignosis, LLC. (2014). E - Learning concepts, trends, applications:

315 Montgomery Street, 8th and 9th Floors. San Francisco, California, CA 94104: United States of America. Retrieved January 14, 2016, from http://www. talentlms.com/elearning/ elearning-101-jan2014-v1.1.pdf.

Esteves, M., Fonseca, B., Morgado, L., \& Martins, P. (2011). Improving teaching and learning of computer programming through the use of the second life virtual world. British Journal of Educational Technology, 42, 4, 624-637. doi: 10.1111/ j.1467-8535.2010.01056.x.

Fernandez, J. (2014). The Microlearning trend: Accommodating cultural and cognitive shifts. Learning Solutions Magazine, December 1.

Foshay, W. R., Silber, K. H., \& Stelnicki, M. B. (2003). Writing training materials that work. San Francisco, CA: JosseyBass/Pfeiffer.

Gagné, R. M., Wager, W. W., Golas, K. C., \& Keller, J. M. (2005). Principles of instructional design (4th ed.). Belmont, CA: Wadsworth/Thompson Learning.

Gomes, A., \& Mendes, A. J. (2007). Learning to program Difficulties and solutions. Proceedings of the International Conference on Engineering Education. Coimbra, Portugal. Retrieved November 5, 2015, from http://icee2007. dei.uc.pt/proceedings/papers/411.pdf. 
Gomes, A., Areias, C., Henriques, J., \& Mendes, A. J. (2008). Aprendizagem de programação de computadores: dificuldades e ferramentas de suporte. Revista Portuguesa de Pedagogia, 42, 2, 161-179. doi:10.14195/1647-8614_42-2_9.

Hansch, A., McConachie, K., Schmidt, P., Hillers, L., Newman, C., $\&$ Schildhauer, T. (2015). The role of video in online learning: Findings from the field and critical reflections. TopMOOC Research Project, Alexander von Humboldt Institut fur Internet und Gesellschaft.

Henderson, K. L. (2007). The effects of prior knowledge activation on learner retention of new concepts in learning objects. Doctoral Thesis. University of Central Florida.

Huertas Barros, E. (2011). Collaborative learning in the translation classroom: Preliminary survey results. JoSTrans - The Journal of Specialised Translation, 2, 42-60. ISSN 1740-357X.

Huo, C., \& Shen, B. (2015). Teaching reform of English listening and speaking in China based on Mobile microlearning. Creative Education, 6, 20, 2221-2226. doi: 10.4236/ce.2015.620228.

Jeffrey, A. S., \& Tricia, K. C. (2011). The impact of problemoriented animated learning modules in a CS1style course (pp. 51-56). Proceedings of the 42nd ACM Technical Symposium on Computer Science Education. New York, NY: ACM.

Job, M. A., \& Ogalo, H. S. (2012). Micro-learning as innovative process of knowledge strategy. International Journal of Scientific Technology Research, 1, 11, 92-96.

Klein, J. D., Spector, J. M., Grabowski, B., \& de la Teja, I. (2004). Instructor competencies: Standards for face-toface, online, and blended settings. Greenwich, CT: Information Age Publishing. Klimkowski, K. (2006). Teamwork as a method in translation. Across Languages and Cultures, 7, 1, 93-103. doi: 10.1556/Acr.7.2006.1.6.

Learning Circuits. (2005). A field guide to learning objects. Retrieved October 18, 2015, from http://ww2. Learning circuits.com/2002/jul2002/smartforce.pdf. 
Malik, S. (2008). C++ programming: From problem analysis to program design (7th ed.). Retrieved January 5, 2016, from http://iit.qau.edu.pk/books/C++\%20Programming\%20From\%2 0Problem\%20Analysis\%20to\%20Program\%20Design\%20[5th \%20Edition].pdf.

Martin, F., Klein, J. D., \& Sullivan, H. (2007). The impact of instructional elements in computer-based instruction. British Journal of Educational Technology, 38, 4, 623 - 636. doi: 10.1111/j.1467-8535.2006.00670.x.

Matthews, R. (2014). Learning objects to improve cognitive understanding in learning introductory programming. $\mathrm{PhD}$ Thesis. Multimedia University, Malasia.

Merrill, M. D. (2002). First principles of instruction. Educational Technology Research and Development, 50, 3, 43-59. doi: 10.1007/BF02505024.

Pappas, C. (2014). 7 micro-elearning techniques to improve performance, E-learning industry Retrieved Mars 5, 2016 from http://elearningindustry.com/7-micro-elearningtechniques-to-improve-performance.

Radoševic, D., Orehovacki, T., \& Lovrencic, A. (2009).Verificator: Educational tool for learning programming. Informatics in Education, 8, 2, 261-280.

Saparkhojayev, N. (2013). Effective teaching of "Parallel Computing" course by using Microlearning technique. World Applied Sciences Journal 28, 6, 842-846.

Siti, S. A. (2012). Learning programming via worked-examples: The effects of cognitive load and learning styles. Doctoral Thesis. University of Sussex: UK.

Vodeclic. (2015). Micro-learning : When less is more: How the bitesized format can revolutionize your training practices and support your enterprise's digital transformation. New York, NY: Vodeclic. 
Vu, P., Fredrickson, S., \& Moore, C. (2017). Handbook of Research on Innovative Pedagogies and Technologies for Online Learning in Higher Education. Hershey, P.A.: IGI Global

Žufic, J., \& Jurcan, B. (2015). Micro-learning and EduPsy LMS. In T, Hunjak, V. Kirinić, M. Konecki (Eds).Central European Conference on Information and Intelligent Systems (pp. 115120). Varaždin: University of Zagreb, Faculty of Organization and Informatics Varaždin, 2015. 